\title{
Laparoscopic adjustable gastric banding, the past, the present and the future
}

\author{
Niccolò Furbetta ${ }^{1}$, Rosa Cervelli ${ }^{2}$, Francesco Furbetta ${ }^{3}$ \\ ${ }^{1}$ General Surgery, Department of Surgery, ${ }^{2}$ Diagnostic and Interventional Radiology, University of Pisa, Pisa, Italy; ${ }^{3}$ General and Laparoscopic \\ Surgery, Leonardo Clinic, Sovigliana-Vinci (Florence), Italy \\ Contributions: (I) Conception and design: N Furbetta, F Furbetta; (II) Administrative support: F Furbetta; (III) Provision of study materials or \\ patients: All authors; (IV) Collection and assembly of data: N Furbetta, R Cervelli; (V) Data analysis and interpretation: All authors; (VI) Manuscript \\ writing: All authors; (VII) Final approval of manuscript: All authors. \\ Correspondence to: Niccolò Furbetta, MD. General Surgery, Department of Surgery, University of Pisa, Via Paradisa 2, Pisa 56124, Italy. \\ Email: n.furbetta@hotmail.it.
}

\begin{abstract}
The laparoscopic implantation of an adjustable gastric banding (LAGB) was first described in 1993. Thereafter, the LAGB underwent to a lot of modifications, revision and refinements to become as it is currently defined. This procedure quickly became one of the most common bariatric surgical operations in the world in the first decade of the 2000s but, over the last few years, it has turned into the fourth more common procedure. A series of more or less clear reasons, led to this decrease of LAGB. The knowledge of the history of the LAGB, of its evolution over the years and its limitations can be the key-point to recognize the reasons that are leading to its decline. The adjustability and the absolute reversibility characteristic of LAGB, make this surgical procedure a "bridge treatment" to allow the specific goal of eradicating obesity.
\end{abstract}

Keywords: Laparoscopic adjustable gastric banding; reversible weight loss surgery; minimally invasive surgery; evolution of laparoscopic adjustable gastric banding (evolution of LAGB)

Submitted May 24, 2019. Accepted for publication Aug 23, 2019.

doi: $10.21037 /$ atm.2019.09.17

View this article at: http://dx.doi.org/10.21037/atm.2019.09.17

\section{Introduction}

The laparoscopic implantation of an adjustable gastric banding (LAGB) was first described by Belachew et al. in 1993 (1). Thereafter, the LAGB underwent to a lot of modifications, revision and refinements to become as it is currently defined. These changes affected both the technological and the surgical techniques, but above all the pre- and post- operative management.

\section{Technological improvement}

Lubomyr Kuzmak is considered a pioneer in bariatric surgery and the inventor of the adjustable gastric banding. His great merit is that he firstly recognized the potentials of adjustability in the gastric banding. In fact, in 1983 Kuzmak projected an adjustable band introducing the advantage of an adjustable inflatable part of the silicon band, which was connected by a tube to a reservoir. On June 1986, he obtained the US patent for the inflatable device (2) and performed his first operation the same month. Subsequently, he described his results showing the superiority of the adjustable gastric band compared with the nonadjustable one he had been using since 1983 .

The laparoscopic gastric banding was for the very first time described in the literature ten years later, in 1993, when Broadbent et al. in Australia, and Catona et al. in Italy, reported on their initial experience. On September 1st, 1993 at the Centre Hospitalier Hutois, Belgium, the first laparoscopic adjustable silicone gastric band was implanted in a patient by Belachew et al. (1). Due to the success of the procedure, the industry started the mass production and marketing of different sizes of adjustable silicon bands ranging from 9.5 to $13 \mathrm{~cm}$ length. Following 
the initial experience, only two sizes $(9.75$ and $10 \mathrm{~cm})$ were maintained, as they could cover all the requirements.

In July 1994, the Lap-Band ${ }^{\circledR}$ System became available on the market to be used by the "trained surgeons". In fact, at first, the BioEnterics, which was the manufacturer of the Lap-Band ${ }^{\circledR}$ (BioEnterics, Carpinteria, CA, USA), did not sell the device to the surgeons before participating in a training program in approved centers. In June 1995, clinical trials in selected US centers were approved by the Food and Drug Administration (FDA). Finally, in 2001, the US FDA approved the clinical application of the Lap-Band ${ }^{\circledR}$ system for the treatment of morbid obesity (3).

This Lap-Band ${ }^{\circledR}$ system consisted of a silicon $13 \mathrm{~cm}$ ring with an inner circumference of 9.75 or $10 \mathrm{~cm}$. The connection tube was $50 \mathrm{~cm}$ long with a fill volume of $4 \mathrm{~mL}$. The subsequent version, the Lap-Band $\mathrm{VG}^{\circledR}$ (Vanguard), approved in 2003, was larger than the previous system, with an inner circumference of $11 \mathrm{~cm}$, and had a fill volume of $10 \mathrm{~mL}$. Furthermore, this modified version was improved by soft, precurved individual sections of the inflatable balloon in order to reduce the risk of the leakages (Omniform technology).

The current device is the result of a final refinement applied in 2006, when the Lap-Band $\mathrm{AP}^{\circledR}$ version (Advanced Platform) was introduced. The Lap-Band $\mathrm{AP}^{\circledR}$ version (Advanced Platform) was designed in two different size: the standard (APS) with a fill volume of $10 \mathrm{~mL}$, and large (APL) with a fill volume of $14 \mathrm{~mL}$. Such variety offered a great range of adjustability in order to respond all patients' anatomical differences. Moreover, the Lap-Band $\mathrm{AP}^{\circledR}$ version included other modifications, such as an easy unlocking mechanism and a 360-degree Omniform inflating balloon component, which improved the reopening procedure and the pressure distribution, respectively (4).

In parallel in the United States, the Realize band, manufactured by the Ethicon Endosurgery Inc. (Cincinnati, OH, USA) was approved by the FDA in 2007 (5). The updated version, called "Realize-C band", was approved in 2009. The latter version stressed the importance of the low inflation pressure with a $11 \mathrm{~mL}$ fill volume. It is also equipped with the unlocking mechanism as well as a prelock position to ease gastric band placement.

\section{Evolution of the surgical technique}

The original technique was described by Belachew and by Favretti $(1,6)$. The key points of the LAGB technique were: (I) pouch volume of 25 cc; (II) perigastric technique;
(III) posterior dissection through the lesser sac, leaving the posterior gastric wall free to move up and down; (IV) two gastro-gastric stiches on the fundus.

The knowledge on the weakness points and on the complications of the LAGB, led to the progressive surgical technique evolution. As a consequence, the above keypoints were modified as follows:

* The volume of the pouch, initially set at $25 \mathrm{cc}$, has been gradually reduced and today we talk about a "virtual pouch" (<15 cc). Moreover, the band-E/G junction distance, which was initially set as $3 \mathrm{~cm}$, has been shortened to $1 \mathrm{~cm}$;

* The "pars-flaccida positioning technique" has become the most widespread technique for (I) the better handling of the instruments and the band; (II) the low complexity in dissection maneuvers; and (III) the low complication rate;

* The posterior dissection above the bursa omentalis is minimized to reduce the risk of posterior slippage.

Finally, some authors suggest to avoid any stitches for an even better result. Furthermore, other improvements were proposed. The gastrostenometer, which was employed in the past to calibrate the pressure at the band level, is no longer used. To prevent a post-operative edema and obstructive acute complications, the connecting tube, is cut outside the abdomen, so that the natural spilling of the liquid guarantees a self-adjusted mechanism, unanimous identify as "point zero". Some authors support the port positioning using mesh fixation on the port. It could have several advantages: avoiding deep incision during the placement; postoperative pain reduction; facilitating port removal (7).

Finally, the shortening of the connection tube is introduced to reduce the risks of complications related to the tube path among ileal loops, or diaphragmatic irritation and shoulder tip pain.

The close relation between bariatric surgery, hiatal hernia and reflux disease, frequently present at the same time in the obese patients, dictated specific rules and indications to be followed.

All the bariatric surgical procedures can worsen or cause reflux and reflux diseases. As a result, the identification of the patients affected by such comorbidities is important to correctly select the right bariatric surgical procedure and possibly solve the contemporary hiatal associated dysfunction.

As to the LAGB, in order to treat the hiatal hernia, 
when present, the diaphragmatic esophageal hiatus is routinely dissected, the hiatal hernia reduced and the crura approximated.

In our center, a routine gastroscopy is made prior the LAGB in order to investigate the presence of direct or indirect signs of hiatal hernia and to exclude other diseases.

To confirm the diagnosis of a significant hiatal hernia two laparoscopic parameters are also evaluated: a deeper than $2 \mathrm{~cm}$ hernia sac, measured by a clinch, and/or the easy passage of the $20 \mathrm{cc}$ inflated balloon of the calibrating tube (gently attracted by the anesthesiologist) throughout the diaphragmatic hiatus.

\section{Pre and post-operative management}

The LAGB was born as a surgical procedure supported by a surgical team. The importance of dedicated surgical skills as well as the presence of an interdisciplinary team (IDT) to assist the patient before and after the surgical procedure, has been rapidly recognized. In 2002, Favretti et al. (8) reported on the importance of the "healthy food choices", the activity and exercise, and the behavioral changes. This study emphasized the relevance in monitoring the comorbidities and the metabolic/nutritional changes during the scheduled post-operative checks, and the power of the communication and collaboration with the patient's primary care provider to support the patient weight control.

Any bariatric surgery is rationally performed within a multidisciplinary team which is the key element for the success of the treatment itself. The IDT professionals are predominantly psychologists, dieticians and motor rehabilitation professionals; the bariatric surgical team is formed and skilled on laparoscopic and endoscopic surgeries, and integrated with dedicated anesthesiologists and aesthetic/reconstructive surgeons.

In the pre-operative period, the IDT prepares the patient in order to cut down risks and failures: organic and behavioral pathologies are highlighted and treated, and, at the same time, the patient is motivated to lose weight. Furthermore, the IDT clearly describes to the patients the complexity of the pathway required to reach the desired weight loss, which include the surgical treatment but also changes in diet and life-style behaviors. Finally, the IDT explains the meaning of the informed consent regarding the procedures (9-11).

Postoperative follow-up gained more and more importance over the years and the timing of scheduled exams, although variable from one center to another, has been established. Follow-up adjustments of the band, initially based only on band filling, are nowadays performed according to numerous variables, such as the radiopaque bolus swallow appearance, the clinical interdisciplinary evaluation of weight loss, the appetite or symptoms, and the patient motivation $(12,13)$.

\section{Results of LAGB}

Obesity is a chronic behavior disease which should be treated by ensuring a long-term benefit. As a result the efficacy of all the bariatric procedures should be assessed in a long term follow-up period. Following this consideration in the analysis were included only studies showing a 3 -year minimum follow-up. Every surgical procedures, and therefore also LAGB, as well as the peri-operatory management, require a variable learning curve. To eliminate the learning phase and to obtain more homogeneous results in our analysis, only series with more than 250 cases were taken into account.

Tables 1 and 2 summarized the results of the included studies about weight loss (estimated at 3- and 5-year follow-up) and erosion and dilatation/herniation of the gastric pouch, which are considered the main long-term complications.

\section{Discussion}

The LAGB, which was the first operation proposed for a laparoscopic approach to the obese patient, due to the technical attraction and encouraging results, spread worldwide. Since its first placement in 1993, LAGB underwent a series of technical, technological and management evolutions (27) (Table 3).

Nowadays, LAGB is a standardized operation and a reproducible technique to evaluate, compare and improve results in the long-term follow-up. Technological improvements, especially the Omniform technology and the different gastric outlet size, led to a reduction in some complications and causes of re-operations. Although some authors documented the complication decrease, it remains difficult to prove because of the coexisting of a series of bias like the different experience and technique in the various studies. As for the technique, the reduction of the initial volume of the gastric pouch (17) was one of the first technical refinements, which greatly reduced the incidence of gastric pouch enlargement/dilation. The impact on the result offered by the pars flaccida technique 
Table 1 Published results after LAGB with at least 250 patients and a minimum follow-up of 3 years in regard to weight loss at 3 and 5 years follow-up

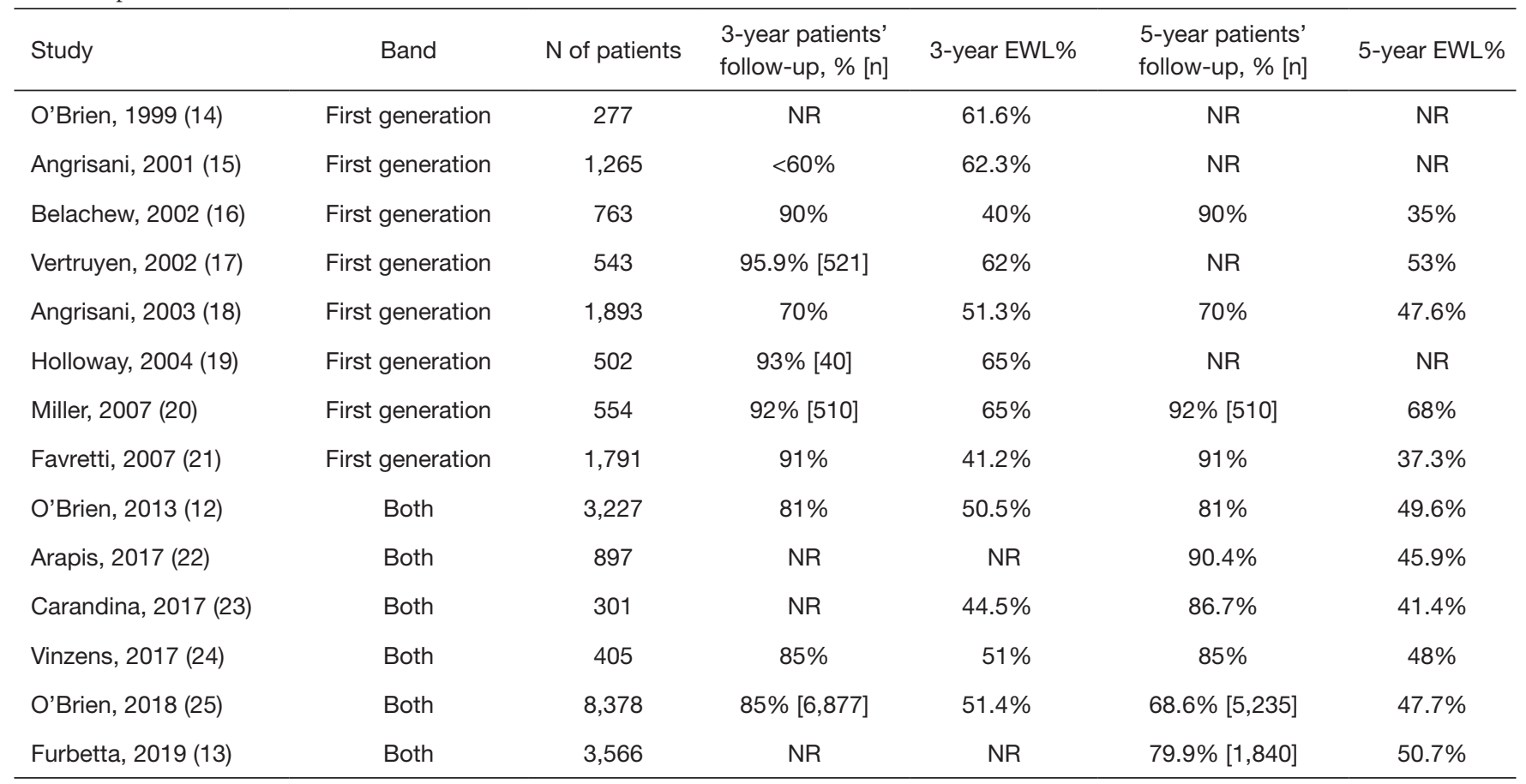

LAGB, laparoscopic adjustable gastric banding; NR, not reported.

is still debated in the literature: some authors reported data on the reduction in the incidence of erosion [from $8.5 \%$ to $2.2 \%$ (12)], slippage and dilatation of the gastric pouch (24), whereas others did not obtained any improvements (22). However, both techniques, the "parsflaccida" and the "perigastric" ones, maintain an important complementary role in specific anatomic circumstances. Another strength point of the surgical technique evolution is the perioperative diagnosis of GERD and hiatal hernia and its surgical treatment contemporary to LAGB. Worsening or de novo GERD, is a well-known problem every bariatric procedure have to deal with. The LAGB's adjustability allows to relieve reflux. In fact, the gradual modification of the pouch outlet is performed in parallel to the patient's behavioral improvements in the eating attitude. The no-compliant patients can benefit from different solutions offered subsequently, thanks to the complete and easy reversibility of the LAGB.

The features of this less invasive technique, adjustable and completely reversible, impose a well-structured interdisciplinary team. The pre-operative program is fundamental to select, educate, inform and motivate patients before undergoing the bariatric surgical operation
$(9,11)$. Postoperative management in bariatric surgery is always of primary importance, and in the LAGB, which is characterized by the adjustability and reversibility, the follow-up is an integral part of the treatment to obtain the better long-term result.

The LAGB is chosen by surgeons to start the learning curve on bariatric procedures. The related, puzzling results contributed to jeopardize its standing and evolution. This procedure, when properly performed by skilled surgeons and supported by an IDT, shows effective results with percentages of excess weight loss ranging from $40 \%$ and $65 \%, 35 \%$ and $68 \%$ at 3 -year and 5 -year follow-up. Furthermore, papers with longer follow-up (more than 15 years) confirm these results with percentages of excess weight loss ranging from $47.9 \%$ and $52.6 \%(13,25)$.

The long-term results obtained in high-volume centers $(13,25)$, both in terms of efficacy and complications, should lead to think, as said by O'Brien, that "the band must not be abandoned" (28).

Future goals of LAGB are strictly related to its mechanism of action: to reinforce the essential interdisciplinary bariatric treatment and to empower surgical operation through adjustability. Adjustability can 
Table 2 Published results after LAGB with at least 250 patients and a minimum follow-up of 3 years in regard to the two main long-term complications, erosion and dilatation/herniation of the gastric pouch

\begin{tabular}{|c|c|c|c|c|}
\hline Study & Band & $\mathrm{N}$ of patients & Dilation-herniation (\%) & Erosion (\%) \\
\hline Angrisani, 2001 (15) & First generation & 1,265 & 5.2 & 1.9 \\
\hline Belachew, 2002 (16) & First generation & 763 & 8 & 0.9 \\
\hline Vertruyen, 2002 (17) & First generation & 543 & 4.6 & 0.92 \\
\hline Holloway, 2004 (19) & First generation & 502 & 5.58 & 0.4 \\
\hline Favretti, 2007 (21) & First generation & 1,791 & 3.9 & 0.9 \\
\hline \multirow[t]{2}{*}{ O’Brien, 2013 (12) } & First generation & 1,857 & 40.5 & 5.3 \\
\hline & Second generation & 1,370 & 6.4 & 0.8 \\
\hline Vinzens, 2017 (24) & Both & 405 & 32.7 & 0.6 \\
\hline \multirow[t]{2}{*}{ Beitner, 2016 (26) } & First generation & 2,241 & 12.27 & 0.45 \\
\hline & Second generation & 470 & 5.95 & 0.2 \\
\hline \multirow[t]{2}{*}{ O’Brien, 2018 (25) } & First generation & 8,378 & 51.7 & 6.1 \\
\hline & Second generation & & 11.3 & 0.69 \\
\hline \multirow[t]{2}{*}{ Furbetta, 2019 (13) } & First generation & 3,566 & 6.9 & 3.1 \\
\hline & Second generation & & 5.5 & 2.3 \\
\hline
\end{tabular}

LAGB, laparoscopic adjustable gastric banding.

counterbalance the failures mainly due to the long-term anatomic and behavior modifications of any operation. An adjustable band allows a partition of the gastric cavity in order to modify the functional pouch outlet to improve restriction or to prepare to revision surgery, in particular to the adjustable by-pass (29). Moreover, the actual limits related to the erosions could be lowered by new devices and new connections to the port.

The present and potential future advantages of LAGB are counterbalanced by the organizing difficulty in scheduling and performing the follow-up for all the patients enrolled. As a consequence, to overcome the "post-surgical management limits", as well as to response to a growing treatment demand, lots of centers propose not-adjustable surgical approaches, which do not require a close follow-up to reach the targeted results.

Our institution provides a section dedicated to obesity, which facilitates patient's recruitment, professionals' cooperation and economic acceptance. In our opinion these premises allow to invest LAGB in the future; in fact, if correctly managed in the peri-operative period, it is an effective technique to achieve the targeted weight loss and food re-education.

In conclusion, the knowledge of the history of the LAGB, of its evolution over the years, of its results and its limits, strictly related to a well-structured IDT, can be the key-points to recognize the reasons that are leading to its decline in favor to "easy", technological surgeries for a growing treatment demand. The adjustability and the absolute reversibility characteristic of LAGB, make this surgical procedure a "bridge treatment" to allow the specific goal of removing obesity. In fact, LAGB, as well as the others bariatric surgeries, does not treat the cause of the obesity, which has a complex pathogenesis, and the surgical medium-long term results highlight the distance between a feasible and a truly effective procedure. Thus, the proper treatment of obesity can be reached only by restoring a healthy life-style and by alimentary re-education. 
Table 3 The evolution of laparoscopic adjustable gastric banding

\begin{tabular}{|c|c|c|c|}
\hline \multicolumn{2}{|c|}{ Technical } & \multicolumn{2}{|c|}{ Pre and post-operative management } \\
\hline $\begin{array}{l}\text { Site of the band } 3 \mathrm{~cm} \text { below the } \mathrm{E}-\mathrm{G} \\
\text { junction }\end{array}$ & $\begin{array}{l}\text { Site of the band } 1 \mathrm{~cm} \text { below the } \\
\mathrm{E}-\mathrm{G} \text { junction }\end{array}$ & $\begin{array}{l}\text { Subjective follow-up } \\
\text { timing }\end{array}$ & $\begin{array}{l}\text { Follow-up timing at scheduled } \\
\text { intervals or in case of need }\end{array}$ \\
\hline Long connection tube & Shortening tube length & $\begin{array}{l}\text { No preoperative } \\
\text { management }\end{array}$ & $\begin{array}{l}\text { Preoperative management } \\
\text { improved by IDT }\end{array}$ \\
\hline $\begin{array}{l}\text { Rare dissection of the diaphragmatic } \\
\text { esophageal hiatus }\end{array}$ & $\begin{array}{l}\text { Common dissection of the } \\
\text { diaphragmatic esophageal hiatus }\end{array}$ & No patient education & Extensive patient education \\
\hline $\begin{array}{l}\text { Subjective intraoperative diagnosis } \\
\text { of hiatal hernia }\end{array}$ & $\begin{array}{l}\text { Measurement of the hiatus with } \\
20 \mathrm{cc} \text { inflated probe }\end{array}$ & $\begin{array}{l}\text { Band adjustment } \\
\text { principally based on band } \\
\text { filling }\end{array}$ & $\begin{array}{l}\text { Based on band filling and IDT } \\
\text { evaluation }\end{array}$ \\
\hline pouch of $25-30 \mathrm{cc}$ & Pouch of $15-20 \mathrm{cc}$ & $\begin{array}{l}\text { No material given to the } \\
\text { patients }\end{array}$ & $\begin{array}{l}\text { A brochure related to LAGB } \\
\text { characteristics }\end{array}$ \\
\hline True pouch at X-ray & Virtual pouch at X-ray & - & - \\
\hline $\begin{array}{l}\text { Initial outlet pressure measured by } \\
\text { gastrostenometer }\end{array}$ & Point 0-autoregulation & - & - \\
\hline $\begin{array}{l}\text { Only peri-gastric positioning } \\
\text { technique }\end{array}$ & $\begin{array}{l}\text { Pars-flaccida or peri-gastric with a } \\
\text { complementary role }\end{array}$ & - & - \\
\hline Two gastro-gastric stitches & $\begin{array}{l}\text { Gastro-gastric stiches to } \\
\text { embedding the silicon band } \\
\text { completely }\end{array}$ & - & - \\
\hline
\end{tabular}

LAGB, laparoscopic adjustable gastric banding; IDT, interdisciplinary team.

Efforts will be directed to further technological developments, mainly aimed at reducing the impact of complications. A slimmer band, alternative adjustment methods, the possibility of simple daily adjustments, new materials, including biological ones, are just a few ideas to work with.

In addition, the long-term results (15-20 years) of the other bariatric procedures, which at the moment are not present as they have a more recent history, will be important to draw definitive conclusions and a more objective comparison.

\section{Acknowledgments}

Funding: None.

\section{Footnote}

Provenance and Peer Review: This article was commissioned by the Guest Editor (Muhammed Ashraf Memon) for the focused issue "Bariatric Surgery" published in Annals of Translational Medicine. The article was sent for external peer review organized by the Guest Editor and the editorial office.

Conflicts of Interest: The focused issue "Bariatric Surgery" was commissioned by the editorial office without any funding or sponsorship. The authors have no conflicts of interest to declare.

Ethical Statement: The authors are accountable for all aspects of the work in ensuring that questions related to the accuracy or integrity of any part of the work are appropriately investigated and resolved.

Open Access Statement: This is an Open Access article distributed in accordance with the Creative Commons Attribution-NonCommercial-NoDerivs 4.0 International 
License (CC BY-NC-ND 4.0), which permits the noncommercial replication and distribution of the article with the strict proviso that no changes or edits are made and the original work is properly cited (including links to both the formal publication through the relevant DOI and the license). See: https://creativecommons.org/licenses/by-nc-nd/4.0/.

\section{References}

1. Belachew M, Legrand MJ, Defechereux TH, et al. Laparoscopic adjustable silicone gastric banding in the treatment of morbid obesity. A preliminary report. Surg Endosc 1994;8:1354-6.

2. Kuzmak L. Gastric banding device. 1986. p. US patent 4,592,339.

3. Food and Drug Administration. Summary of safety and effectiveness: LAP-BAND Adjustable Gastric Banding System-PMA: P000008 2001.

4. Food and Drug Administration. Summary of safety and effectiveness data (SSED): LAP-BAND Adjustable Banding System, Allergan - PMA: P000008/SO17 2010.

5. Food and Drug Administration. Summary of safety and effectiveness: Realize Adjustable Gastric Band (Model 2200-X), Ethicon - PMA: P070009 2007.

6. Favretti F, Cadiere GB, Segato G, et al. Laparoscopic Adjustable Silicone Gastric Banding: Technique and Results. Obes Surg 1995;5:364-71.

7. Akkary E, Olgers F. Subcutaneous Placement of Lap Band Port Without Fascial Fixation Provides Safe and Durable Access. Obes Surg 2014;24:1987-91.

8. Favretti F, O’Brien PE, Dixon JB. Patient management after LAP-BAND placement. Am J Surg 2002;184:38S-41S.

9. Rebibo L, Maréchal V, De Lameth I, et al. Compliance with a multidisciplinary team meeting's decision prior to bariatric surgery protects against major postoperative complications. Surg Obes Relat Dis 2017;13:1537-43.

10. Talarico JA, Torquati A, McCarthy EM, et al. PreLap-Band group education in Medicaid population: does it really make a difference? Surg Obes Relat Dis 2010;6:356-60.

11. Busetto L, Pilone V, Schettino AM, et al. Determinants of health-related quality of life in morbid obese candidates to gastric banding. Eat Weight Disord 2012;17:e93-100.

12. O'Brien PE, MacDonald L, Anderson M, et al. Longterm outcomes after bariatric surgery: Fifteen-year follow-up of adjustable gastric banding and a systematic review of the bariatric surgical literature. Ann Surg
2013;257:87-94.

13. Furbetta N, Gragnani F, Flauti G, et al. Laparoscopic adjustable gastric banding on 3566 patients up to 20 -year follow-up: Long-term results of a standardized technique. Surg Obes Relat Dis 2019;15:409-16.

14. O'Brien PE, Brown WA, Smith A, et al. Prospective study of a laparoscopically placed, adjustable gastric band in the treatment of morbid obesity. Br J Surg 1999;86:113-8.

15. Angrisani L, Alkilani M, Basso N, et al. Laparoscopic Italian experience with the Lap-Band. Obes Surg 2001;11:307-10.

16. Belachew M, Belva PH, Desaive C. Long-term results of laparoscopic adjustable gastric banding for the treatment of morbid obesity. Obes Surg 2002;12:564-8.

17. Vertruyen M. Experience with Lap-Band System ${ }^{\circledR}$ up to 7 years. Obes Surg 2002;12:569-72.

18. Angrisani L, Furbetta F, Doldi SB, et al. Lap Band ${ }^{\circledR}$ adjustable gastric banding system: The Italian experience with 1863 patients operated on 6 years. Surg Endosc 2003;17:409-12.

19. Holloway JA, Forney GA, Gould DE. The Lap-Band is an effective tool for weight loss even in the United States. Am J Surg 2004;188:659-62.

20. Miller K, Pump A, Hell E. Vertical banded gastroplasty versus adjustable gastric banding: prospective long-term follow-up study. Surg Obes Relat Dis 2007;3:84-90.

21. Favretti F, Segato G, Ashton D, et al. Laparoscopic Adjustable Gastric Banding in 1,791 Consecutive Obese Patients: 12-Year Results. Obes Surg 2007;17:168-75.

22. Arapis K, Tammaro P, Parenti LR, et al. Long-Term Results After Laparoscopic Adjustable Gastric Banding for Morbid Obesity: 18-Year Follow-Up in a Single University Unit. Obes Surg 2017;27:630-40.

23. Carandina S, Tabbara M, Galiay L, et al. Long-Term Outcomes of the Laparoscopic Adjustable Gastric Banding: Weight Loss and Removal Rate. A Single Center Experience on 301 Patients with a Minimum Follow-Up of 10 years. Obes Surg 2017;27:889-95.

24. Vinzens F, Kilchenmann A, Zumstein V, et al. Longterm outcome of laparoscopic adjustable gastric banding (LAGB): results of a Swiss single-center study of 405 patients with up to 18 years' follow-up. Surg Obes Relat Dis 2017;13:1313-9.

25. O'Brien PE, Hindle A, Brennan L, et al. Long-Term Outcomes After Bariatric Surgery: a Systematic Review and Meta-analysis of Weight Loss at 10 or More Years for All Bariatric Procedures and a Single-Centre Review of 20-Year Outcomes After Adjustable Gastric Banding. 
Obes Surg 2019;29:3-14.

26. Beitner MM, Ren-Fielding CJ, Fielding GA. Reducing complications with improving gastric band design. Surg Obes Relat Dis 2016;12:150-6.

27. Belachew M, Legrand MJ, Vincent V. History of LapBand®: From dream to reality. Obes Surg 2001;11:297-302.
28. Brown WA, O'Brien PE. The Band Must Not Be Abandoned. Obes Surg 2017;27:1911-3.

29. Furbetta F, Gambinotti G. Functional Gastric Bypass with an Adjustable Gastric Band. Obes Surg 2002;12:876-80.

Cite this article as: Furbetta N, Cervelli R, Furbetta F. Laparoscopic adjustable gastric banding, the past, the present and the future. Ann Transl Med 2020;8(Suppl 1):S4. doi: 10.21037/atm.2019.09.17 